\title{
Measurements of Ground Acoustic Environments for Small Solid Rocket Motor Firings
}

$162^{\text {nd }}$ Meeting of the Acoustical Society of America

31 October-4 November 2011, San Diego, California

Bruce Vu (NASA Kennedy Space Center)

Ken Plotkin (Wyle Laboratories) 


\section{At Stake}

- Mobile launcher deck and tower are exposed to severe acoustic environments during launch.

- These environments, if not properly managed, can weaken ground support equipment and result in structure failure. 


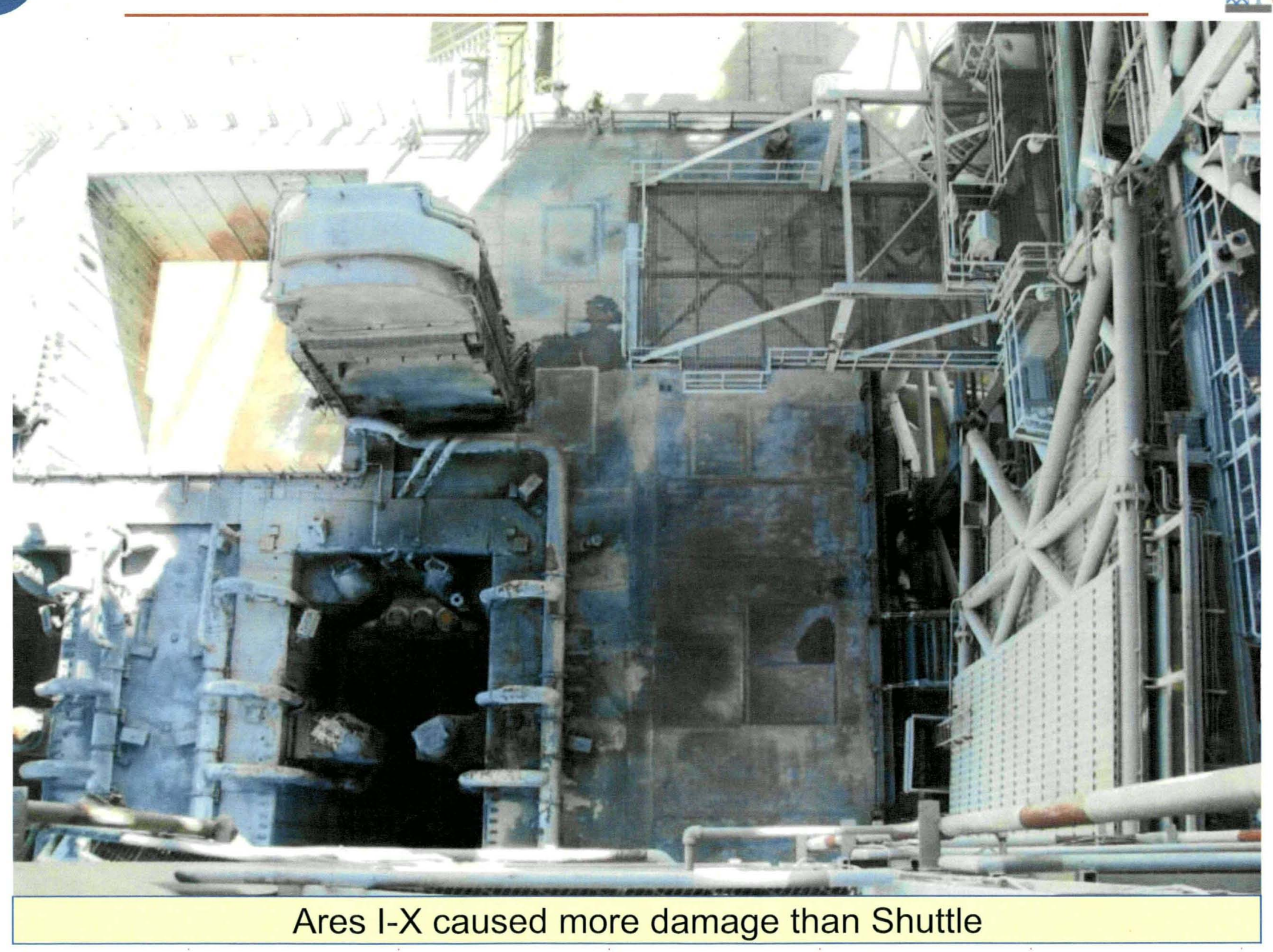









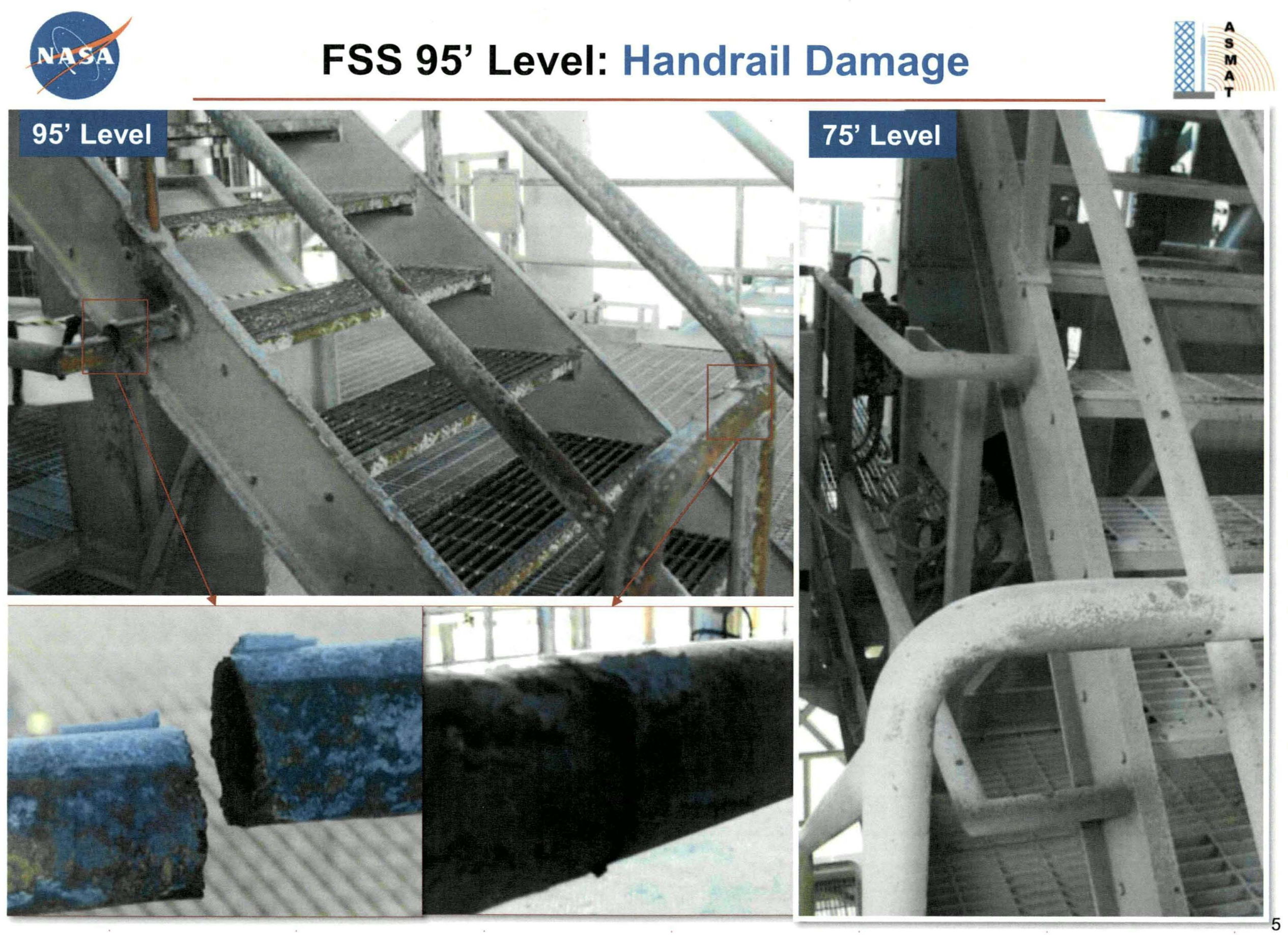




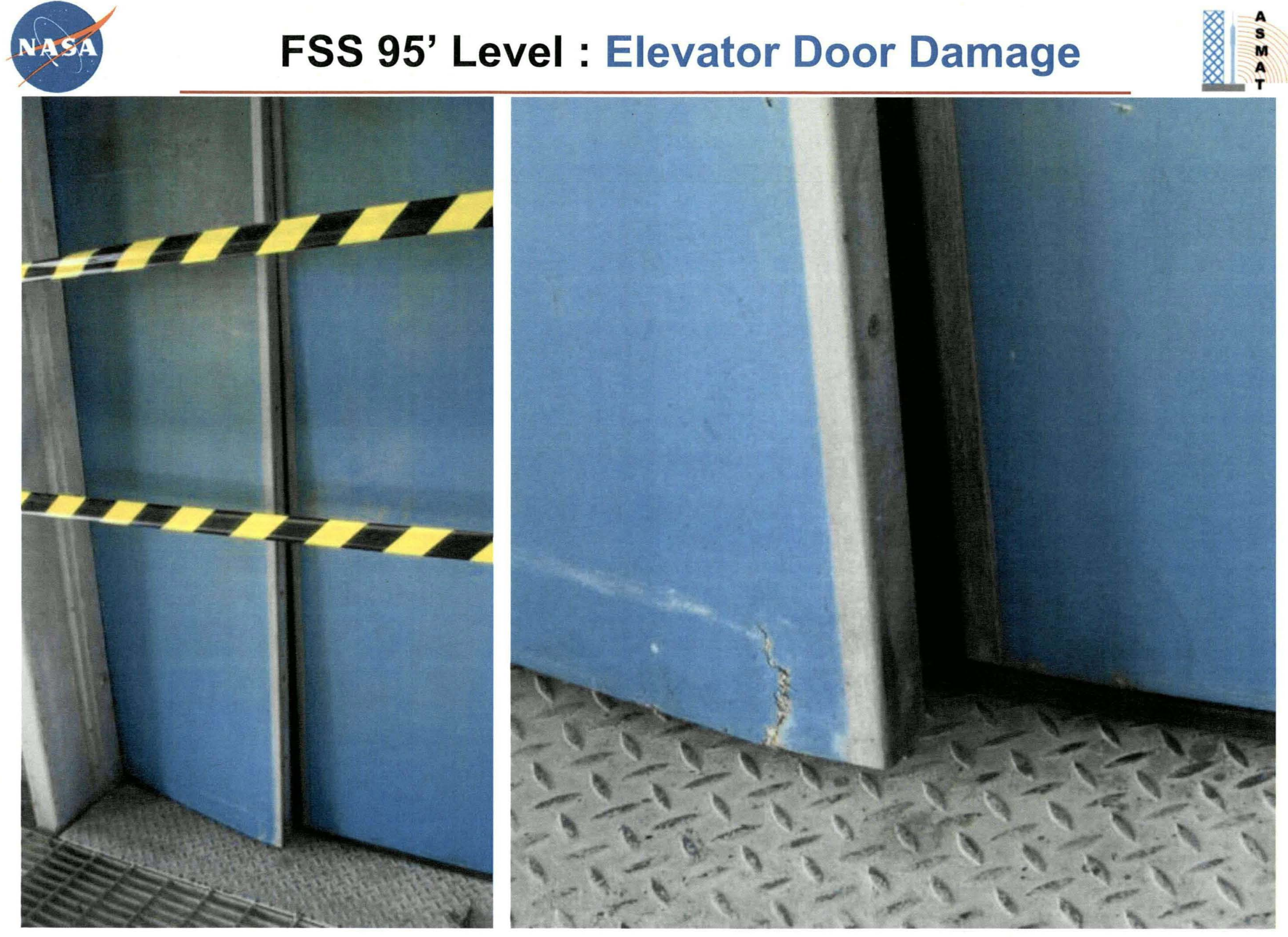




\section{Challenges}

- The ground acoustic environments are different than the vehicle acoustic environments, typically more severe because of the close proximity of the rocket plume, which often involves direct impingement.

- Ground acoustics are more difficult to predict, and their measurement and data reduction remain challenging. 


\section{ASMAT Outline}

- Objectives

- Data Analysis

- Test Matrix

- Instrumentation

- Time-history Data

- Data Processing

- Discussion of Results

- Tube Resonance

- Conclusion 


\section{ASMAT Objectives}

- Characterize the acoustic ground environment with and without water suppression systems.

- Validate the ground acoustic prediction based on scaling of Saturn V data.

- Validate the semi-empirical acoustic analysis documented in Wyle report WR-08-39, "Ares I Near Field Launch Acoustic Environments, including Water Suppression, Drift and Impingement." 
Test Matrix

\begin{tabular}{|c|c|c|c|c|c|c|c|c|c|c|c|}
\hline \multirow{2}{*}{ Test } & \multirow{2}{*}{ Objective } & \multicolumn{2}{|c|}{ Location } & \multicolumn{6}{|c|}{ Water Systems } & \multirow[b]{2}{*}{ Test Date } & \multirow{2}{*}{ r } \\
\hline & & $\begin{array}{c}\text { Bevation } \\
\text { (Feet) }\end{array}$ & Drift (in) & Waterbags & $\begin{array}{l}\text { Trench } \\
\text { Water } \\
\text { (gpm) }\end{array}$ & $\begin{array}{c}\text { Exhaust } \\
\text { Hole Water } \\
\text { (gpm) }\end{array}$ & $\begin{array}{l}\text { Rainbird } \\
\text { (gpm) }\end{array}$ & $\begin{array}{l}\text { Total } \\
\text { water } \\
\text { (gpm) }\end{array}$ & $\begin{array}{l}\text { Rainbird } \\
\text { Ww/Wp }\end{array}$ & & \\
\hline 1 & IOP Series. Hold down case with water bags. & 0 & & Yes & 873 & 291 & & 1164 & N/A & $11 / 5 / 2010$ & \\
\hline 2 & IOP Series. Hoid down case without w ater bags. & 0 & & $\mathrm{No}$ & 873 & 291 & & 1164 & N/A & $11 / 10 / 2010$ & \\
\hline 3 & $\begin{array}{l}\text { IOP Series. Dry case. Test primarily for IOP } \\
\text { measurements. }\end{array}$ & 0 & & & & & & 0 & N/A & $11 / 18 / 2010$ & \\
\hline 4 & $\begin{array}{l}\text { Bevation Series. Purpose is to find the elevation of } \\
\text { max SPL. No rainbird water. IOP measurements not } \\
\text { necessary }\end{array}$ & $2.5(50)$ & 4.625 & & 873 & 291 & & 1164 & N/A & $1 / 20 / 2011$ & \\
\hline 5 & $\begin{array}{l}\text { Bevation Series. Purpose is to find the elevation of } \\
\text { max SPL. Nb rainbird water. }\end{array}$ & $5(100)$ & 6.875 & & 873 & 291 & & 1164 & N/A & $1 / 28 / 2011$ & \\
\hline 6 & $\begin{array}{l}\text { Bevation Series. Purpose is to find the elevation of } \\
\text { max SPL. No rainbird water. }\end{array}$ & $7.5(150)$ & 8.375 & & 873 & 291 & & 1164 & N/A & $2 / 3 / 2011$ & \\
\hline 7 & Bevation Series. Repeat at max SPL. & 5 & 6.875 & & 873 & 291 & & 1164 & N/A & $2 / 15 / 2011$ & \\
\hline 8 & $\begin{array}{l}\text { Rainbird Series. Purpose is to find effective flow rate } \\
\text { of rainbirds at max SF. }\end{array}$ & 5 & 6.875 & & 873 & 291 & 566 & 1730 & 2 & $2 / 23 / 2011$ & \\
\hline 9 & $\begin{array}{l}\text { Rainbird Series. Purpose is to find effective flow rate } \\
\text { of rainbirds at max SR. }\end{array}$ & 5 & 6.875 & & 873 & 291 & œe1 & 2155 & 3.5 & $3 / 2 / 2011$ & Completed \\
\hline 10 & Modified Rainbird Series (No LM) & 5 & 6.875 & & 873 & 291 & 801 & 2155 & 3.5 & $5 / 12 / 2011$ & \\
\hline 11 & Modified Bevation Series (No LM, No Rainbird) & 5 & 6.875 & & 873 & 291 & & 1164 & N/A & $5 / 18 / 2011$ & \\
\hline 12 & Modified Rainbird Series (No LM) & 5 & 6.875 & & 873 & 291 & 1275 & 2438 & 4.5 & $5 / 24 / 2011$ & \\
\hline 13 & No Drift (No LM) & 5 & 0 & & 873 & 291 & 901 & 2155 & 3.5 & $6 / 7 / 2011$ & \\
\hline 14 & No Drift (No LM) No Rainbirds & 5 & 0 & & 873 & 291 & & 1164 & N/A & $6 / 14 / 2011$ & \\
\hline 15 & Modified Bevation Series (No LM, No Rainbird) & 10 & 0.875 & & 873 & 281 & & 1164 & N/A & $6 / 27 / 2011$ & \\
\hline 16 & Modified Rainbird Series (No LM) & 10 & 8.875 & & 873 & 291 & 891 & 2155 & 3.5 & $6 / 30 / 2011$ & \\
\hline 17 & Contingency (Dry at 5) & 5 & 0 & & 0 & 0 & 0 & 0 & $N / A$ & $7 / 12 / 2011$ & \\
\hline
\end{tabular}




\section{Instrumentation}

- 39 ASMAT locations for ground acoustics measurements

- 28 are on the Tower, 7 on ML deck, and 4 under ML

- Sensor naming convention:

Gxx.Lz

where $\mathrm{xx}=$ sensor number,

$\mathrm{L}=$ location ( $\mathrm{T}:$ Tower, M:Deck, F:underside)

$z=$ ordered number within the location

- Sensor inventory

- 49 microphones, model number B\&K 4944-B.

- 20 PCB S112A22 pressure probes

- Sensor mounting

- Tower microphones flush mounted in cylindrical holders for protection

- Microphones sometimes recessed or partially covered for protection.

- Resonances must be calculated to adjust data 


\section{GA Instrumentation Calibration}

- All sensors sent to MSFC Calibration Lab for pre-test calibration

- These sensitivities were loaded in the Test Definition File

- All data used in the analysis uses these traceable sensitivities

- During test operations:

- All microphones and pressure probes underwent a pre-test check-out with a calibrated pistonphone

- This verified that the sensor diaphragms were functional and responsive at an expected amplitude prior to test

- Post-test check-out day of hotfire, using pistonphone

- This was to determine if the sensors were still functional and if not, were replaced prior to the next test

- Pre- and post-test ground acoustic pistonphone results were reported in hotfire debrief charts 

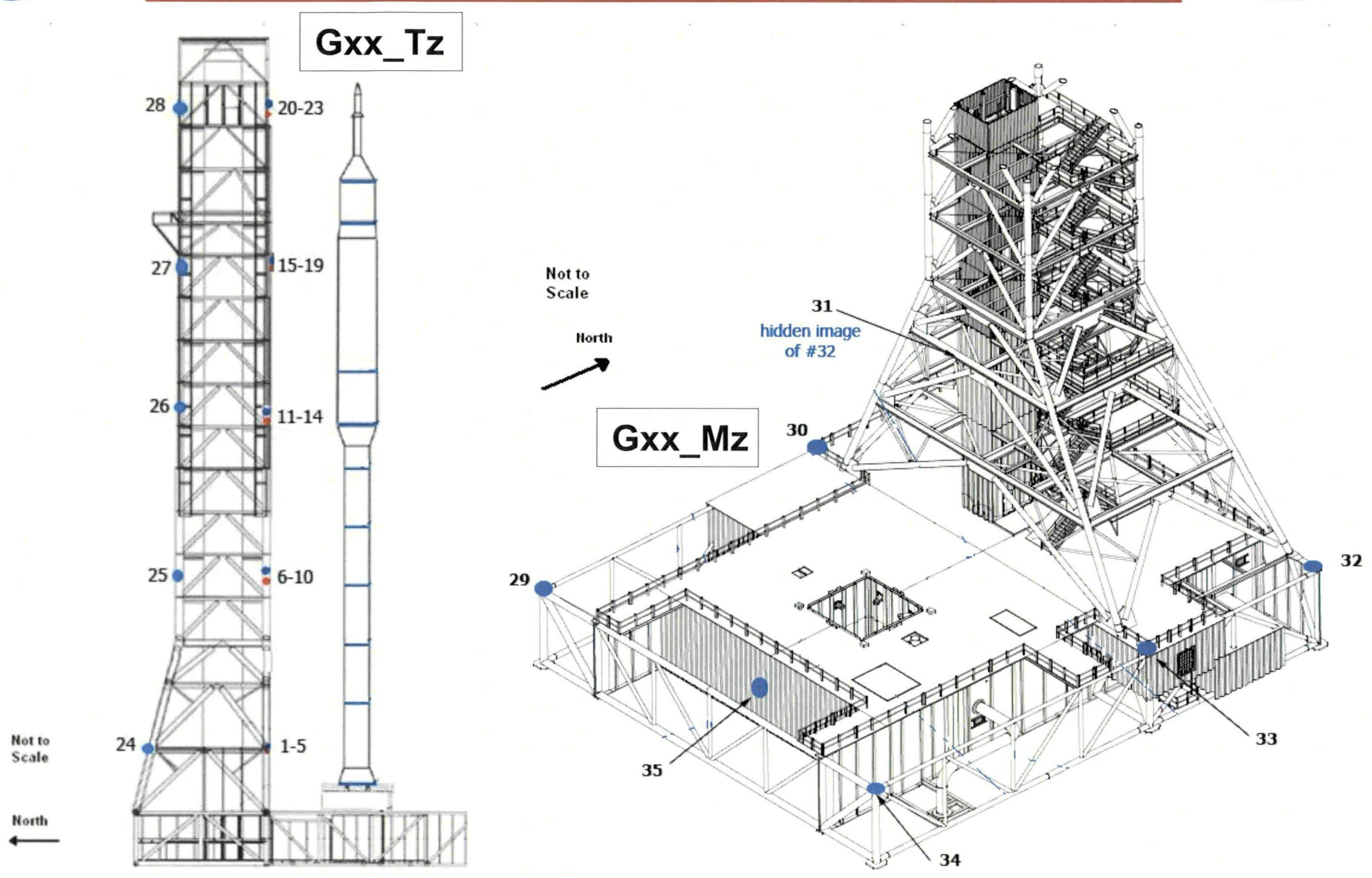


\section{Instrumentation Layout}

Mobile Launcher View from Underside

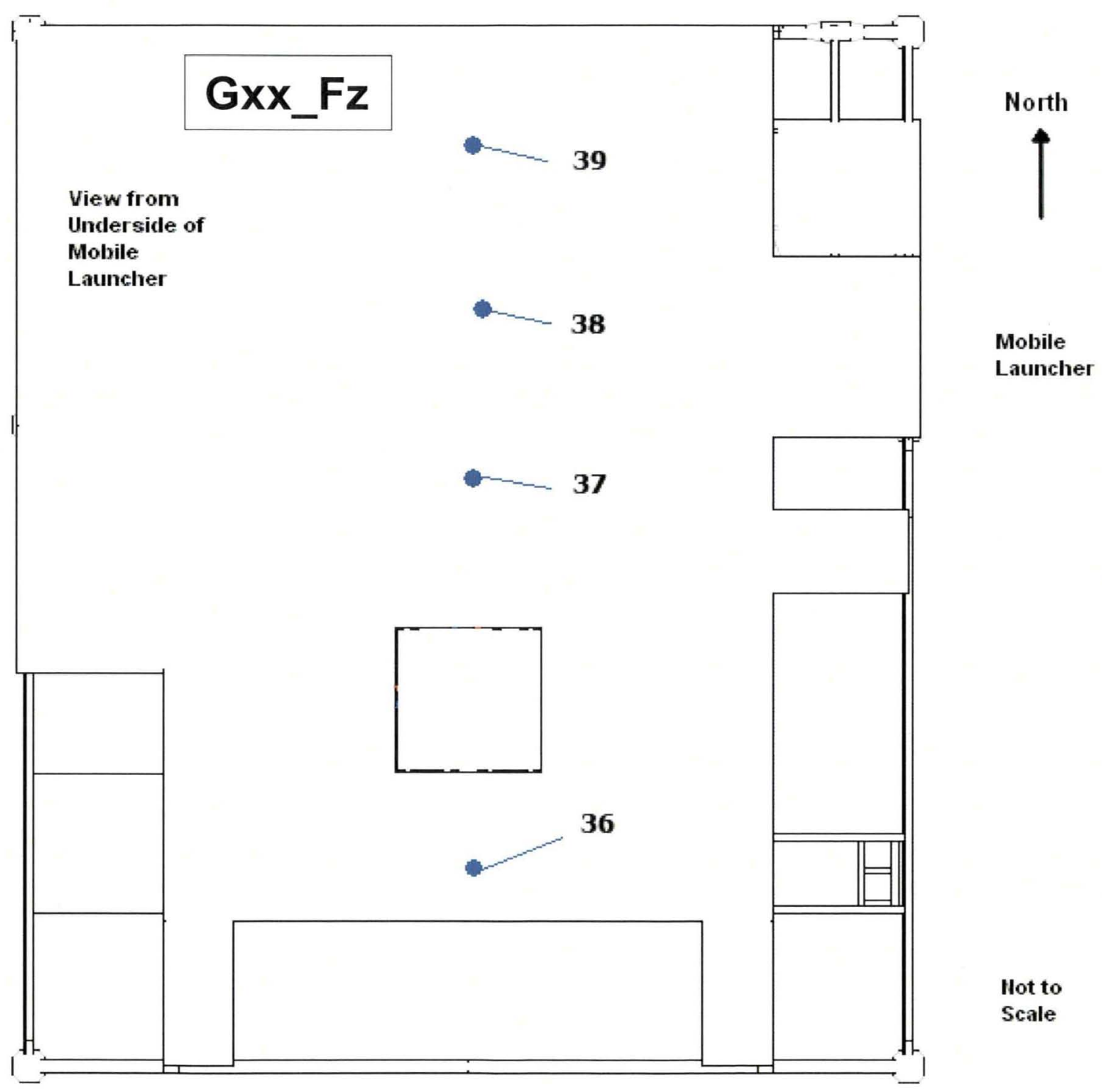




\section{DATA ANALYSIS}


- Use High Speed Data Viewer

- Confirm the validity of raw data

- Check chamber pressure to determine the time offset

- Decide an analysis time block

- Process data using FFT

- Review spectral plots for any anomolies

- Remove transient effect

- Remove cavity resonance

- Compare results for effects of

- Elevation

- Rainbirds

- Drifts

- Launch Mount

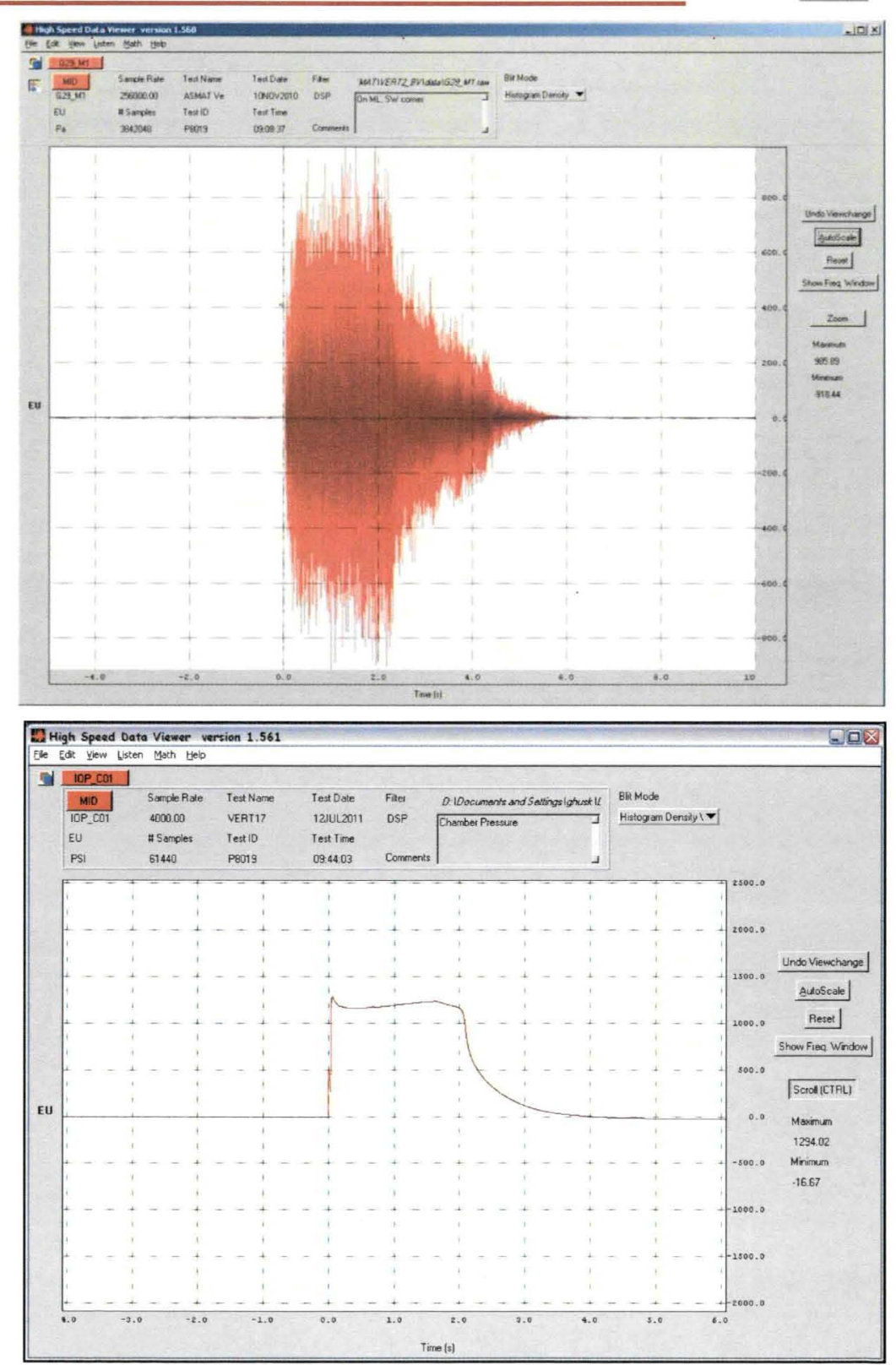




\section{Data Processing}

- Hann windowing

- Offset time $=1.0 \mathrm{sec}$

- Sampling rate $=256,000$ samples per second

- Analysis time block $=0.5 \mathrm{sec} \rightarrow 128,000$ samples

- FFT size $=2^{16}=65,536$ samples $256,000 / 65,536 \rightarrow$ low freq limit $=4 \mathrm{~Hz}(0.2 \mathrm{~Hz}$ full scale $)$

- Overlaps to improve statistics, $\mathrm{N}=6$

- $1 / 3$ octave band number $=10-50 \rightarrow f=10 \mathrm{~Hz}-100 \mathrm{kHz}$

- Filter out early transient effects by excluding data prior to offset time (Filter time $=0.1-1.0$ sec depending on the time-history data) 







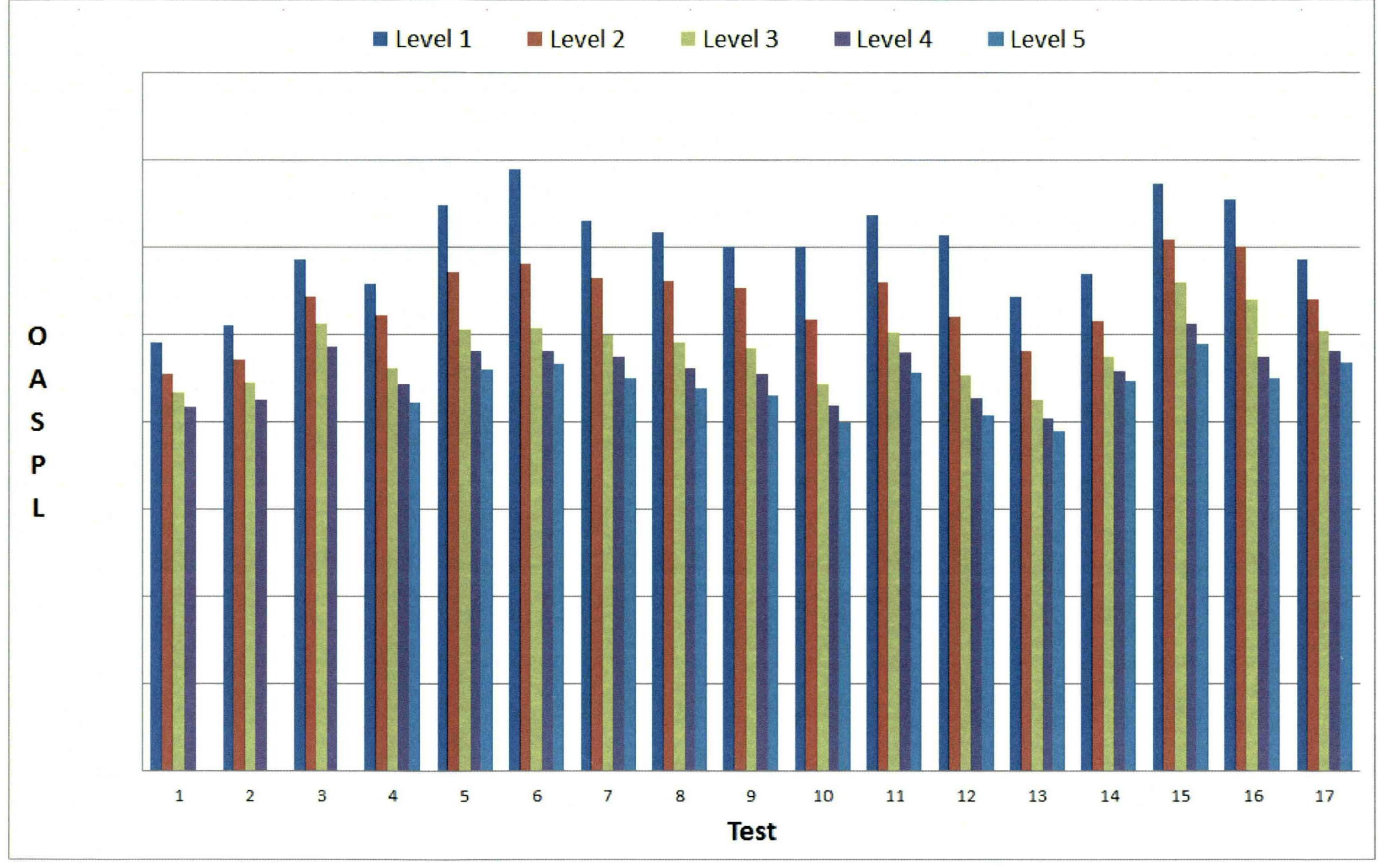




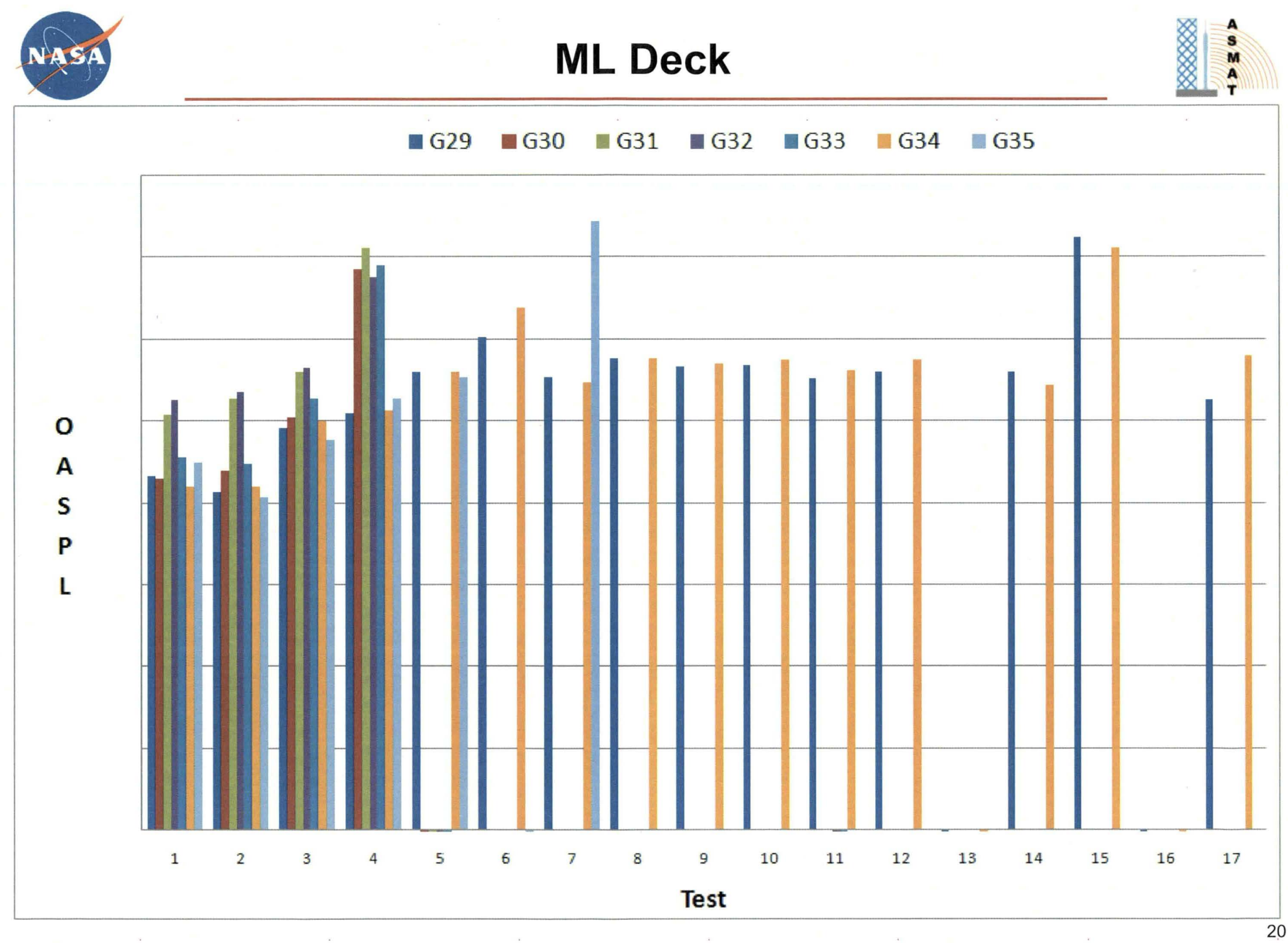




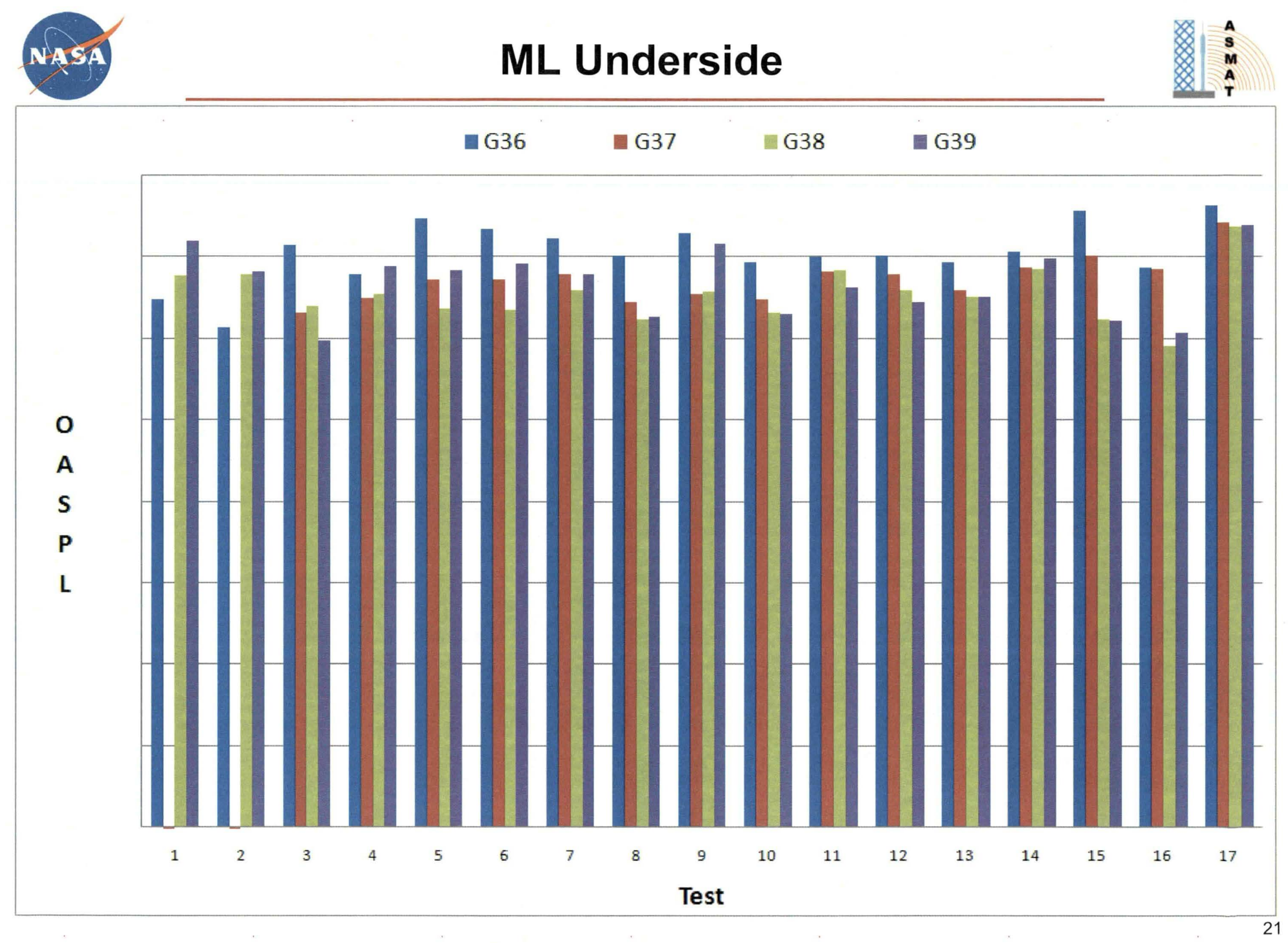


- B\&K 4144 Microphone response defined without protective grid

- Frequency Response Function (FRF) measured for eight rocket firings (Bennett and Lee, 2010)

- Statistical results

- Not yet applied to ASMAT - will be for final analysis

- Plume impingement failure of B\&K mics at lower levels. Replace with PCB, and:

- Vert 7 and Vert 8: Protective caps on some T1 and T2 microphones

- Vert 9: Some microphones recessed

- Resonances from caps/recess need to be computed and applied

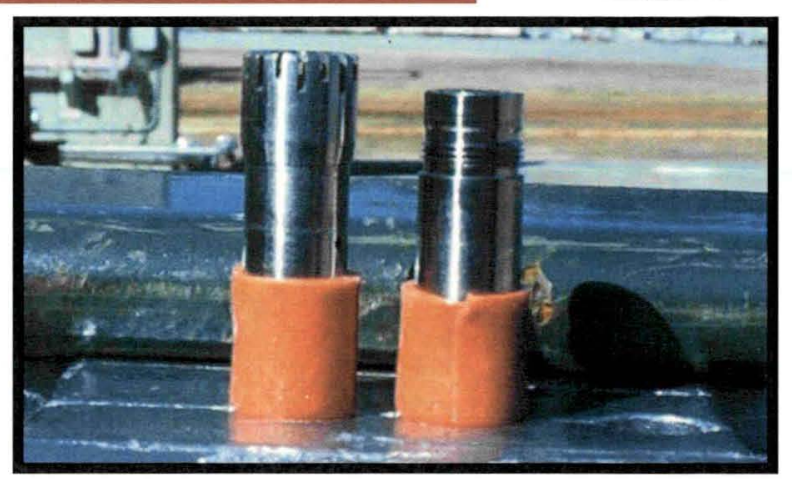

Sensor Side

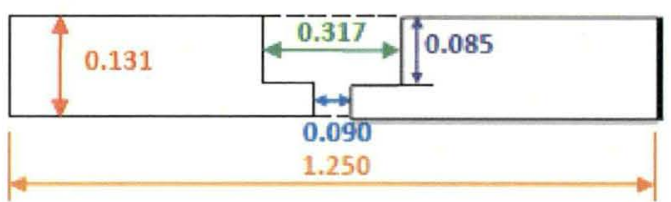

Plume Side

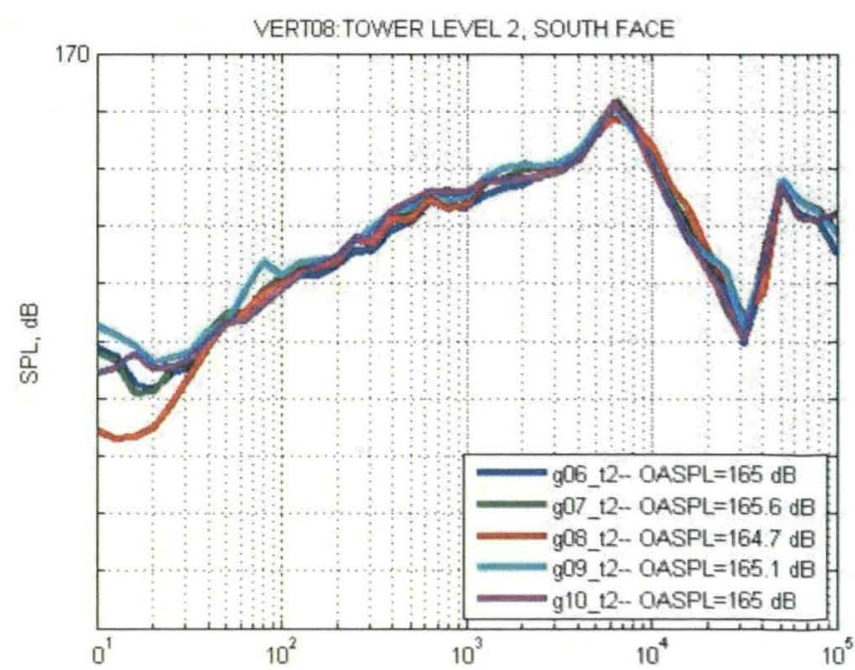




\section{Cavity Tone (Chris Tam/FSU)}

- Outstanding Challenges

- Size of Computation Domain

- Outflow Boundary Conditions

- Turbulence Modeling



FIGURE 11 Computation domain for cavity tone problem

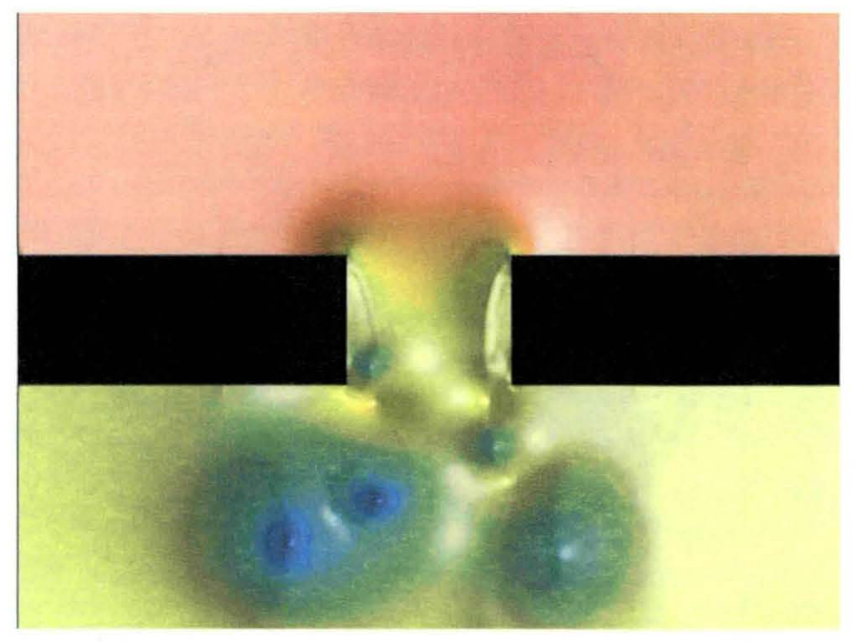

FIGURE 10a Vortex shedding at a $90^{\circ}$ slit

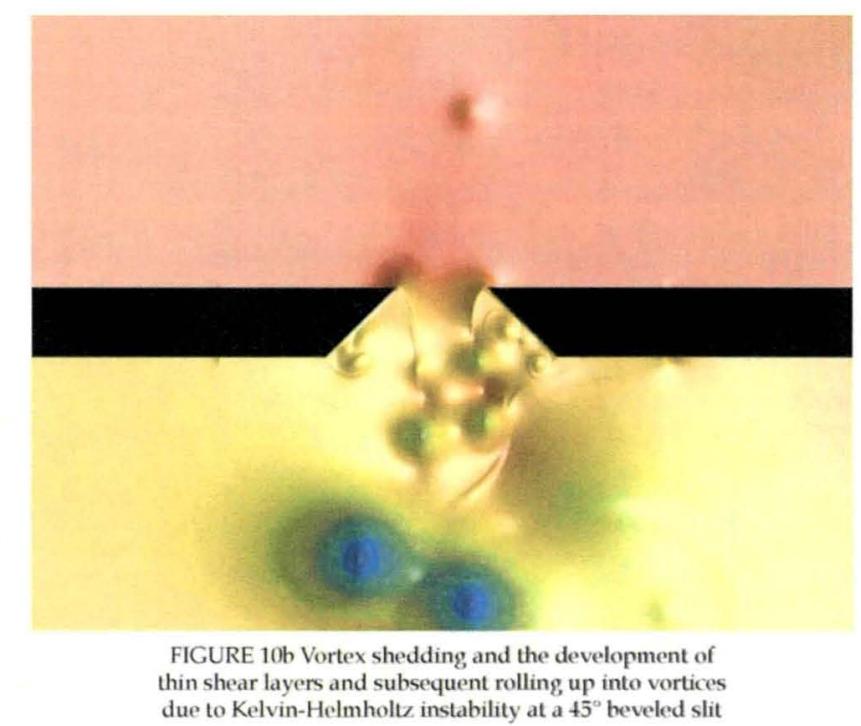




\section{Cavity Tone (Devos \& Lafon/France)}

- Numerical Method

- 2-D Euler
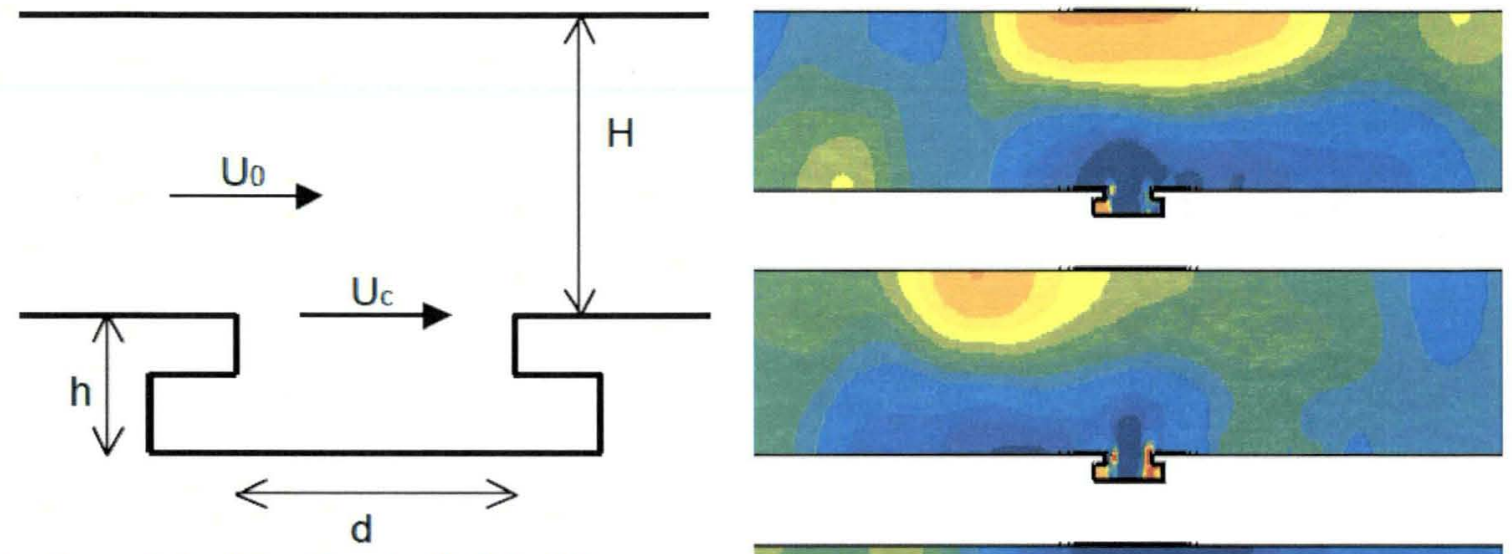

Figure 3 : the original cavity studied in this paper
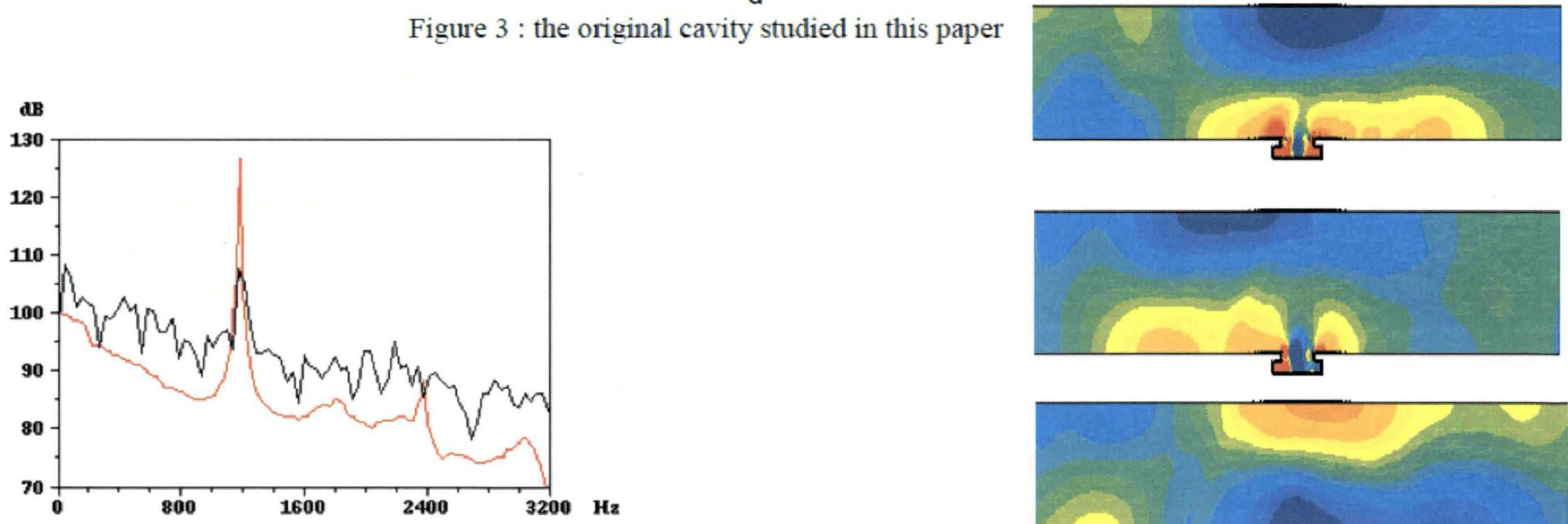

Figure $4:$ pressure spectra in the cavity for the original cavity

- experiment : higher level for the tone frequency
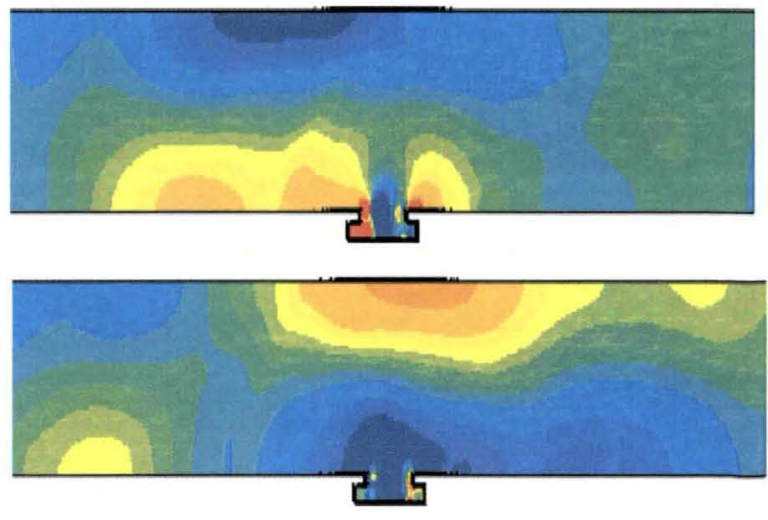

Pressure

- computation : higher level for broadband fluctuations 


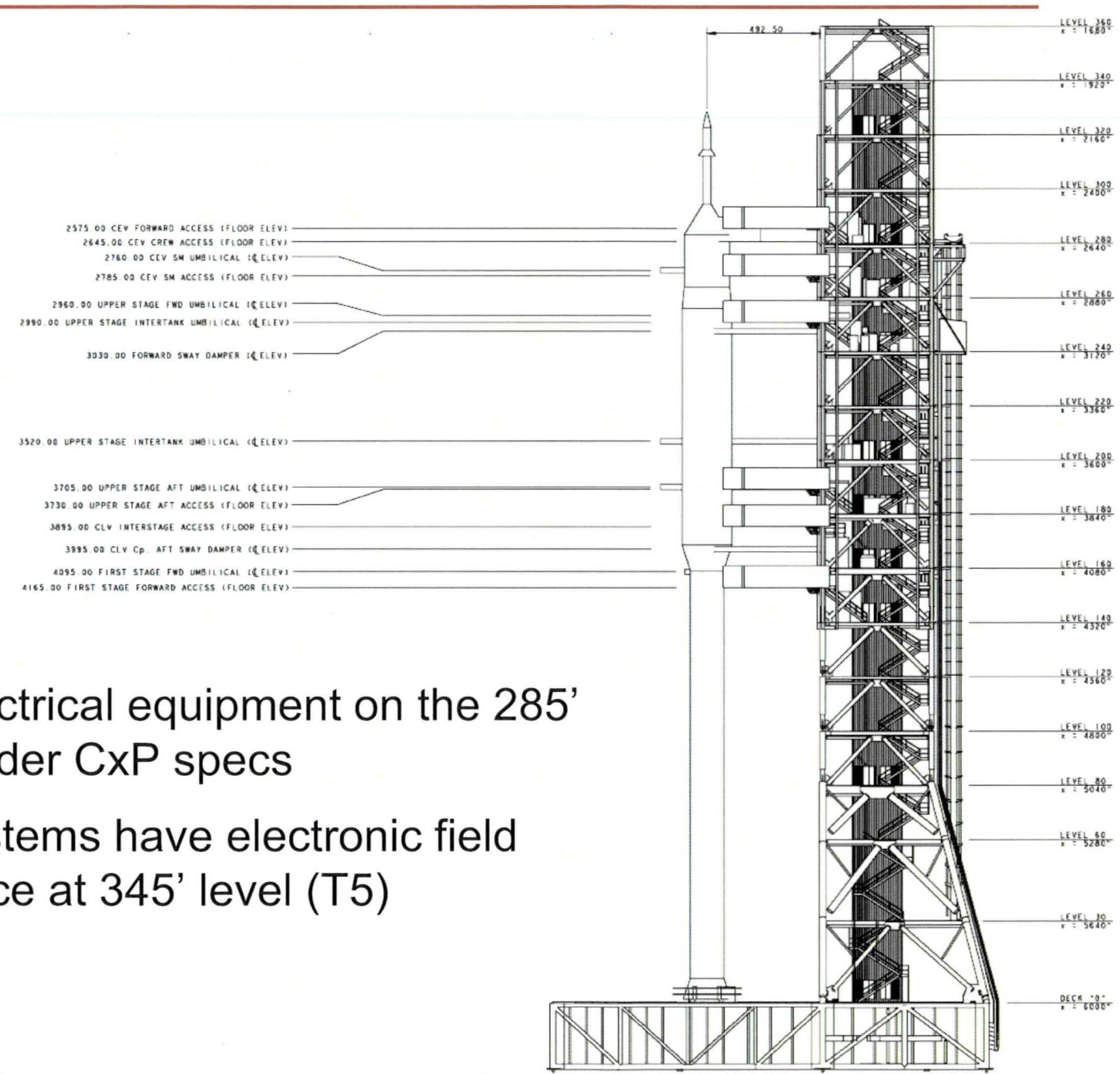




\section{Ares I - Elevation Effects}

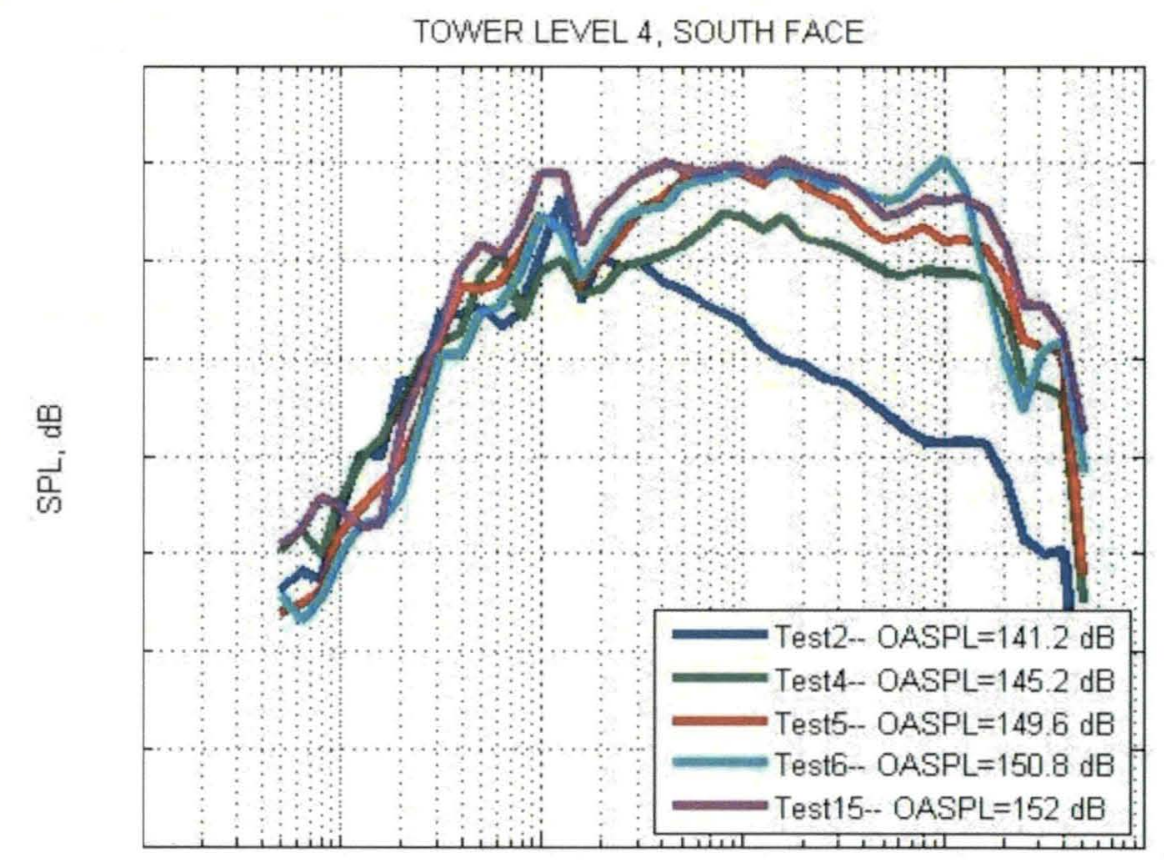

One-third Octave Frequency, $\mathrm{Hz}$

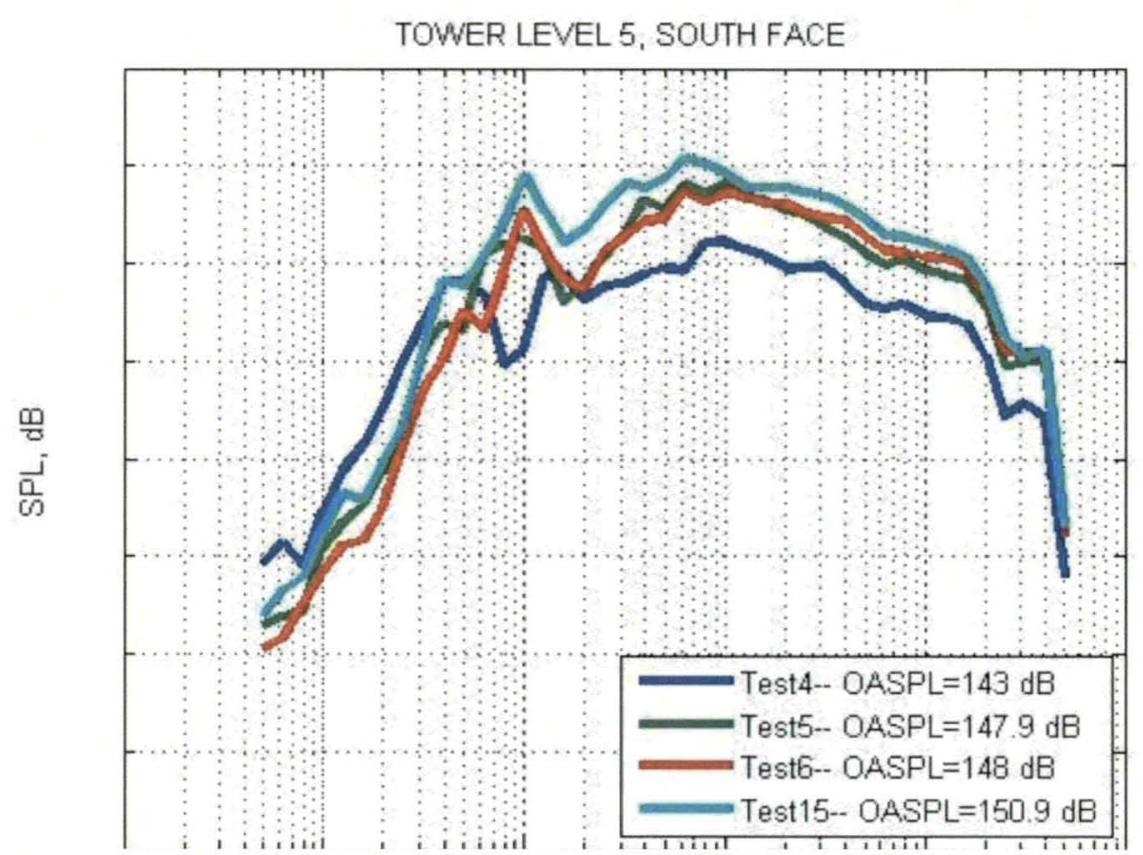

One-third Octave Frequency, $\mathrm{Hz}$

Test02: $z=0.0, \quad x=0.000 ", 0 \mathrm{gpm}$

Test04: $z=2.5^{\prime}, x=4.625 ", 0 \mathrm{gpm}$

Test05: $z=5.0, x=6.875 ", 0 \mathrm{gpm}$

Test06: $z=7.5^{\prime}, x=8.375^{\prime \prime}, 0 \mathrm{gpm}$

Test15: $z=10 ., x=9.975 ", 0 \mathrm{gpm}$ 


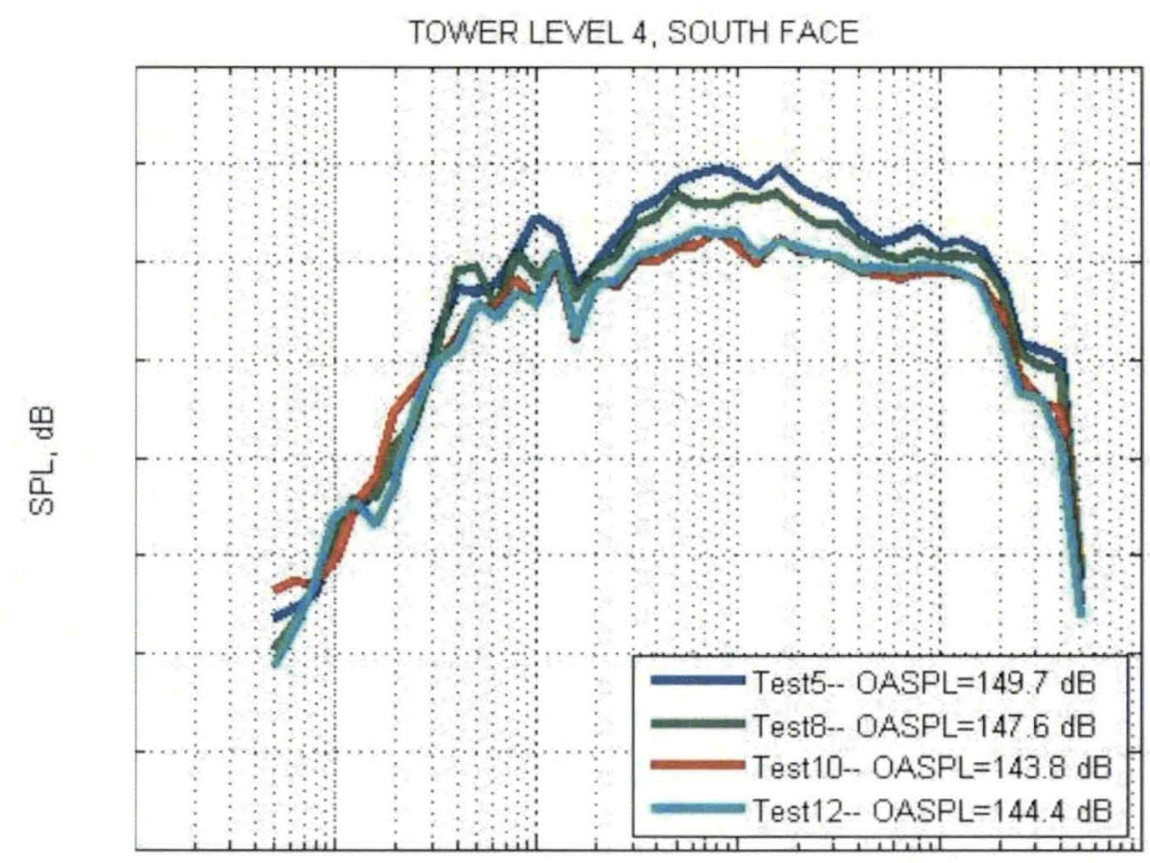

One-third Octave Frequency, $\mathrm{Hz}$

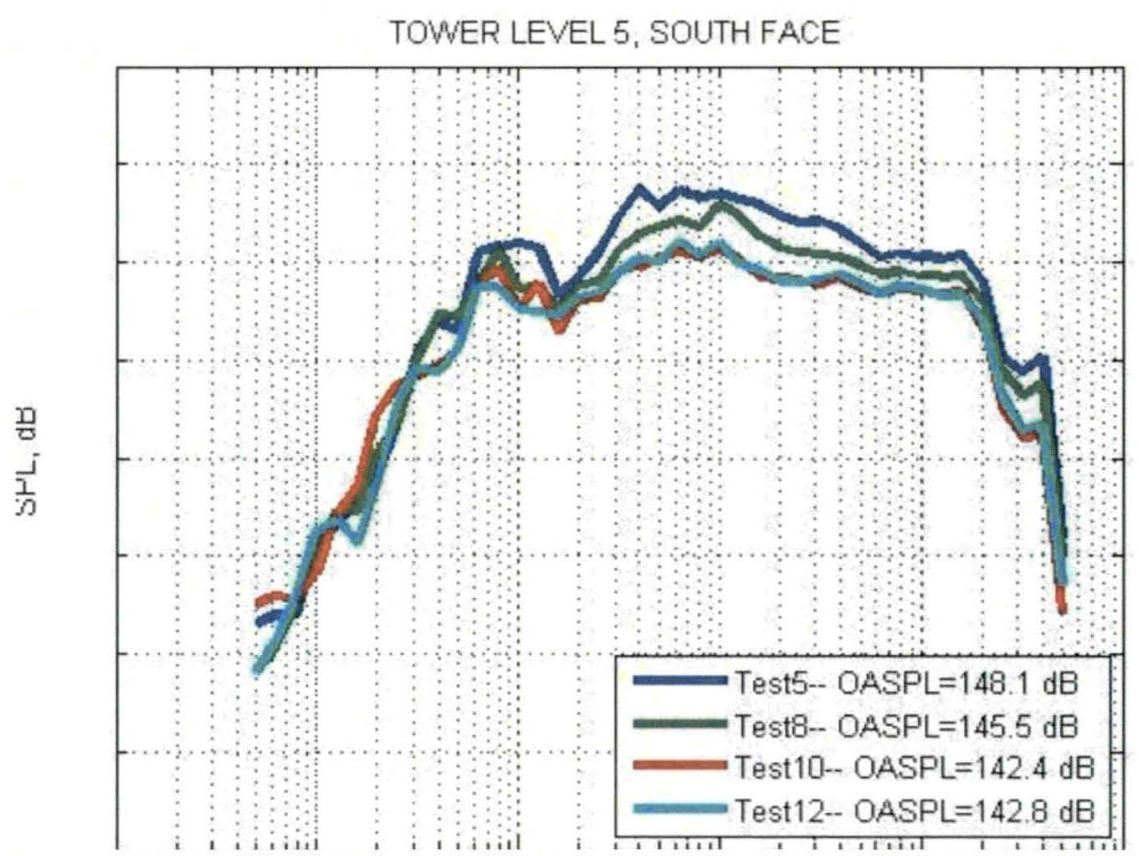

One-third Octave Frequency, $\mathrm{Hz}$

Test05: $z=5.0, \quad x=6.875 ”, \quad 0 \mathrm{gpm}$

Test08: $z=5.0, \quad x=6.875^{\prime \prime}, \quad 566 \mathrm{gpm}$

Test10: $z=5.0, x=6.875^{\prime \prime}, 991 \mathrm{gpm}$

Test12: $z=5.0, x=6.875^{\prime \prime}, 1275 \mathrm{gpm}$ 


\section{Ares I - Drift Effects}

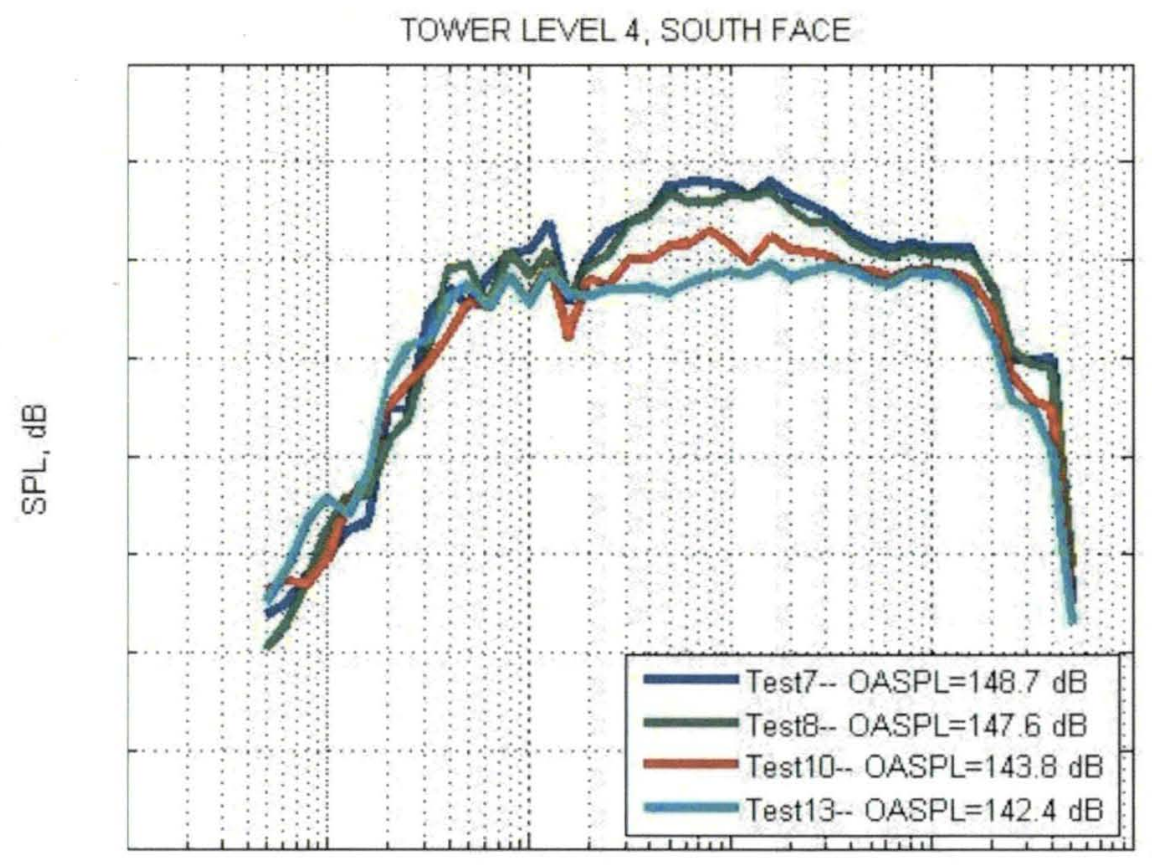

One-third Octave Frequency, $\mathrm{Hz}$

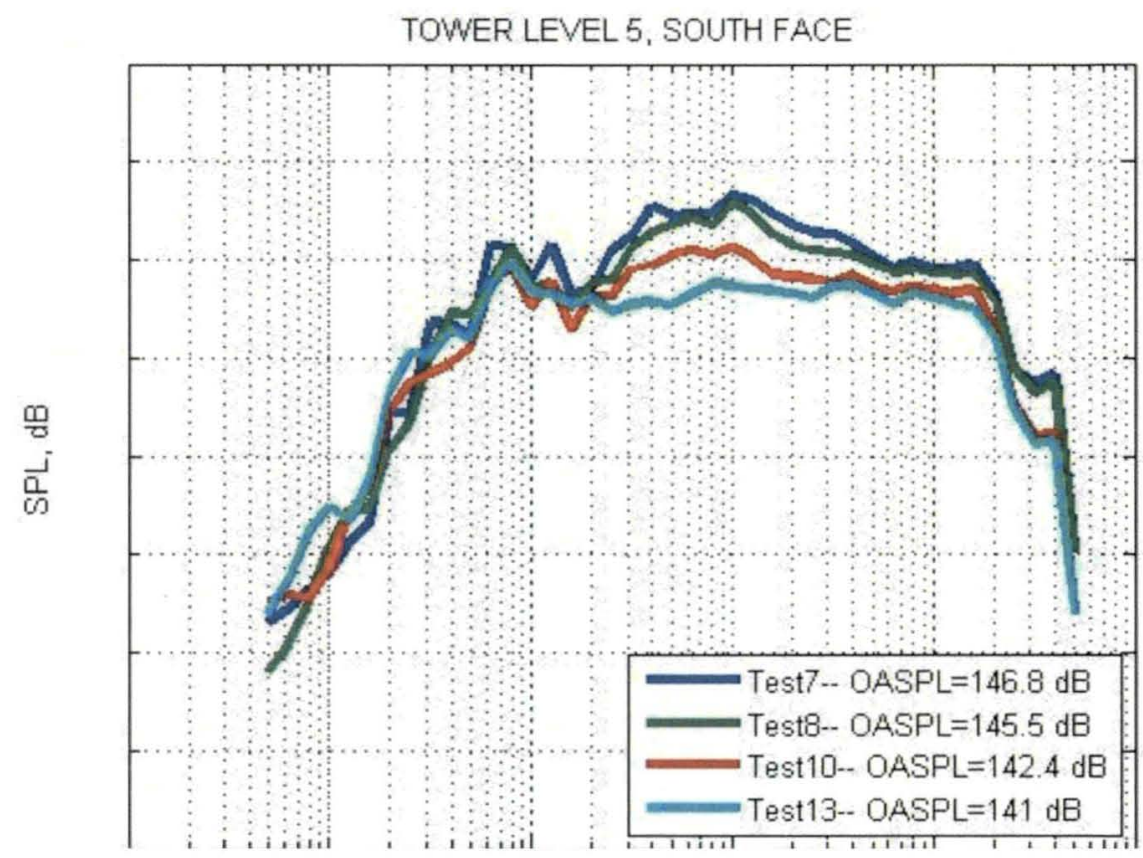

One-third Octave Frequency, $\mathrm{Hz}$

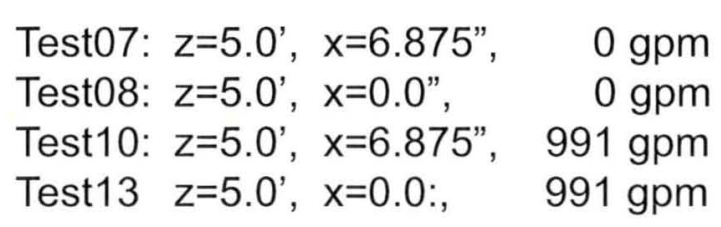




\section{Ares I - Launch Mount Effects}

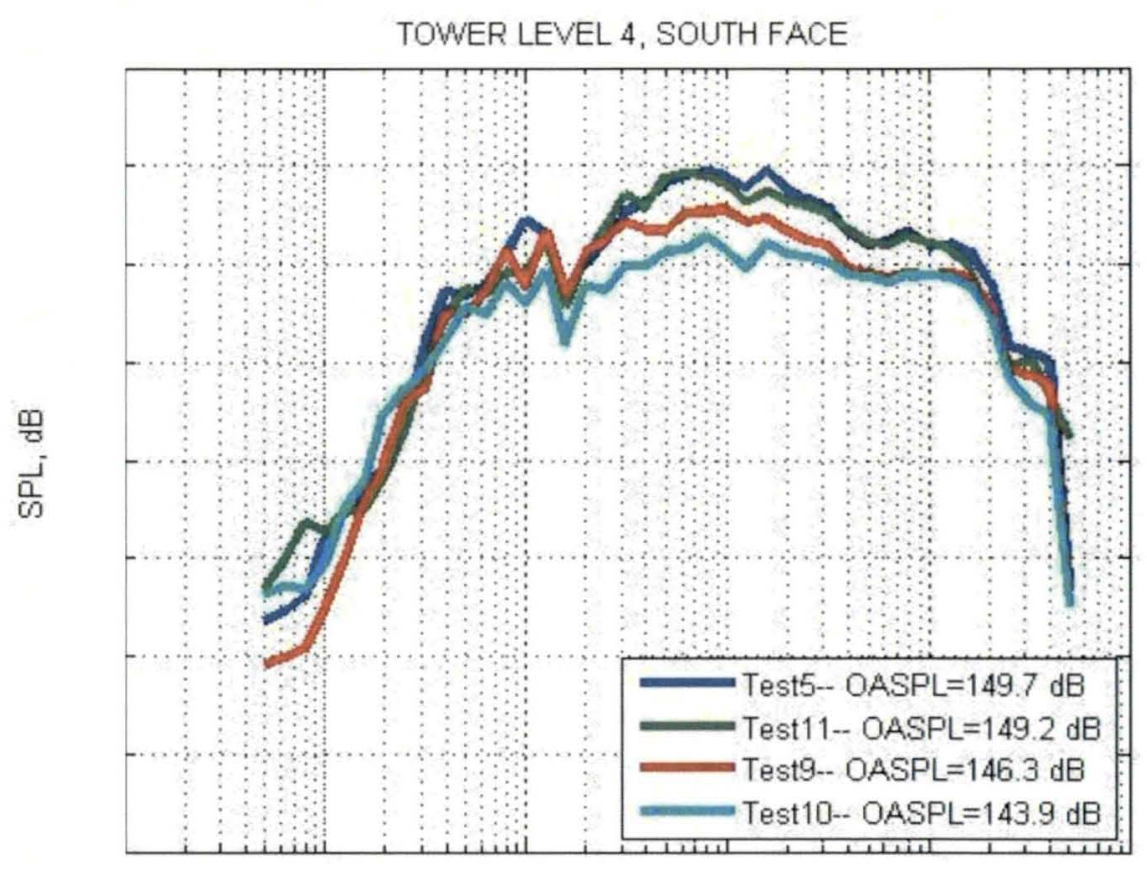

One-third Octave Frequency, $\mathrm{Hz}$

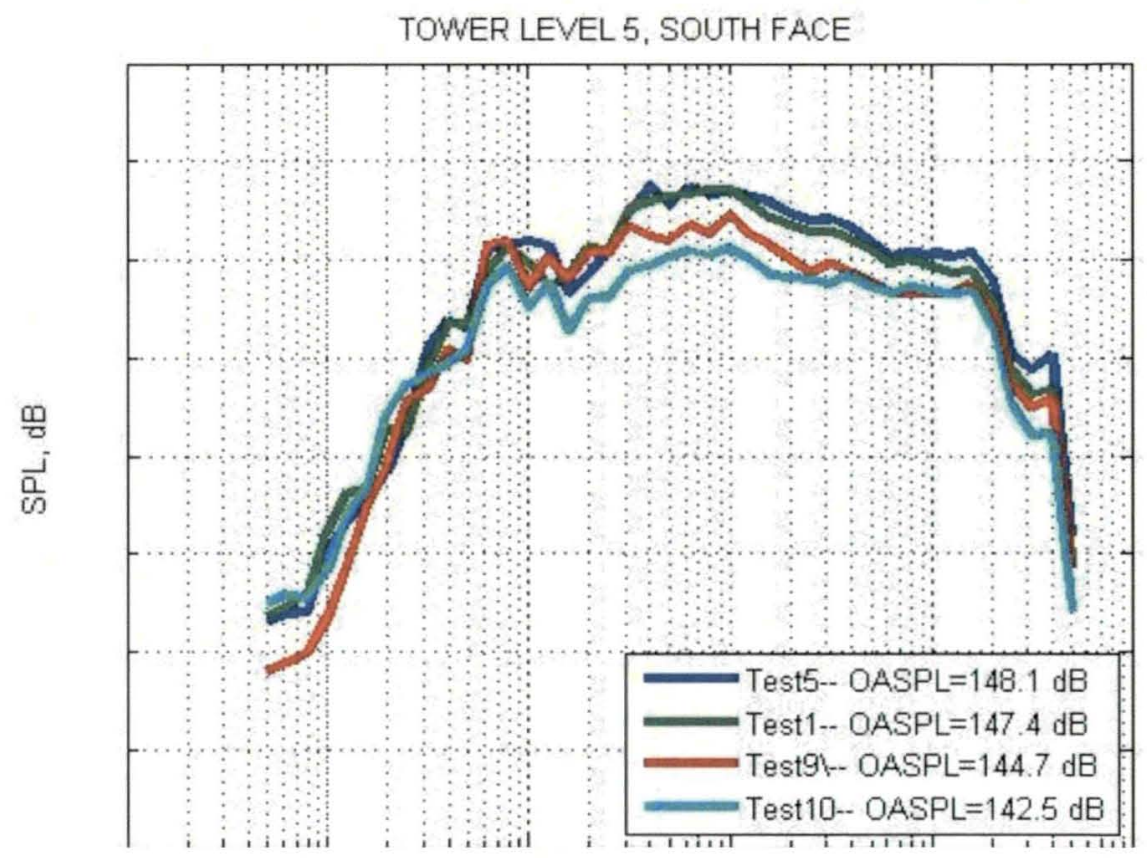

One-third Octave Frequency, $\mathrm{Hz}$

$$
\begin{gathered}
0 \text { gpm, with LM } \\
0 \text { gpm, no LM } \\
991 \text { gpm, with LM } \\
991 \text { gpm, no LM }
\end{gathered}
$$




\section{Conclusion}

- General trends, falloff with distance, as expected

- Plume impingement and IOP greatly affected acoustic measurements on the ML deck and Tower lower level below nozzle exit plane, making post-processing task difficult

- ML Deck sensors (G29, G34) overloaded

- All other sensors (ML Underside) probably overloaded, some were salvaged by filtering out the time window

- Maximum SPL occurred at relatively high vehicle altitude

- Rainbirds can reduce up to $6 \mathrm{~dB}$ at locations of interest

- Vehicle drift increases SPL, up to $1.4 \mathrm{~dB}$ OASPL

- Launch Mount increases SPL, up to $3 \mathrm{~dB}$ OASPL

- To be accomplished

- Tube resonance analysis is required for recessed mics

- Compare results with scaled Saturn-V and PAD predictions 


\section{Conclusion (cont'd)}

- ASMAT provided valuable insights to the launch-induced environments

- Ground acoustic measurements remained a challenge; very difficult to collect data on the ML Base and lower Tower levels

- Environments were higher than predicted

- Beamforming results showed acoustics due to plume impingement to be different from NASA-SP-8072

- GSE should be placed on the North side of the Tower, if possible

- LM added adverse effects to the environments. Remove it if possible

- Vehicle drift only increased the environments slightly. Plume impingement is more of a concern during vehicle drift

- While rainbirds help reduce environments, ML Base and Tower can withstand the load without them 